\title{
Comparison of the effect of sevoflurane or propofol anesthesia on the regional cerebral oxygen saturation in patients undergoing carotid endarterectomy: a prospective, randomized controlled study
}

Sanghee Park', Keunbae Yook ${ }^{1}$, Kyung Yeon Yoo', Jeong II Choi ${ }^{1}$, Hong-Beom Bae ${ }^{1}$, Youngwook You', Baoyuan Jin ${ }^{1,2}$ and Seongtae Jeong ${ }^{1,2^{*}}$ (D)

\begin{abstract}
Background: The monitoring of regional cerebral oxygen saturation $\left(\mathrm{SrO}_{2}\right)$ using near-infrared spectroscopy is useful method to detect cerebral ischemia during. Sevoflurane and propofol decrease cerebral metabolic rate $\left(\mathrm{CMRO}_{2}\right)$ in a similar manner, but the effects on the cerebral blood flow (CBF) are different. We hypothesized that the effects of sevoflurane and propofol on $\mathrm{SrO}_{2}$ were different in patients with deficits of CBF. This study compared the effect of sevoflurane and propofol on $\mathrm{SrO}_{2}$ of patients undergoing cerebral endarterectomy (CEA).

Method: Patients undergoing CEA were randomly assigned to the sevoflurane or propofol group $(n=74)$. The experiment was preceded in 2 stages based on carotid artery clamping. The first stage was from induction of anaesthesia to immediately before clamping of the carotid artery, and the second stage was until the end of the operation after clamping of the carotid artery. Oxygen saturation $\left(\mathrm{SrO}_{2}, \mathrm{SpO}_{2}\right)$, haemodynamic variables (blood pressure, heart rate), respiratory parameters (end-tidal carbon dioxide tension, inspired oxygen tension), concentration of anesthetics, and anesthesia depth (bispectral index score) were recorded.

Results: During stage 1 period (before carotid artery clamping), the mean value of the relative changes in $\mathrm{SrO}_{2}$ was higher $(P=0.033)$ and the maximal decrease in $\mathrm{SrO}_{2}$ was lower in the sevoflurane group compared with the propofol group $(P=0.019)$ in the contralateral (normal) site. However, there is no difference in ipsilateral site (affected site). $\mathrm{SrO}_{2}$ decreased after carotid artery clamping and increased after declamping, but the difference was not significant between two groups. Changes in mean arterial blood pressure was lower in sevoflurane group than propofol group after the carotid artery declamping $(P=0.048)$.
\end{abstract}

Conclusion: Propofol-remifentanil anesthesia was comparable with sevoflurane-remifentanil anesthesia in an aspect of preserving the $\mathrm{SrO}_{2}$ in patients undergoing carotid endarterectomy.

Trial registration: Clinical Trials.gov identifier: NCT02609087, retrospectively registered on November 18, 2015.

Keywords: Carotid endarterectomy, Regional cerebral oxygen saturation, Near-infrared spectroscopy, Propofol, Sevoflurane

\footnotetext{
* Correspondence: anesjst@jnu.ac.kr

'Department of Anesthesiology and Pain Medicine, Chonnam National

University Medical School and Hospital, 42 Jebong-ro, Dong-gu, Gwangju

61469, South Korea

${ }^{2}$ The Brain Korea 21 Project Center for Biomedical Human Resources,

Chonnam National University, Gwangju, South Korea
}

(c) The Author(s). 2019 Open Access This article is distributed under the terms of the Creative Commons Attribution 4.0 International License (http://creativecommons.org/licenses/by/4.0/), which permits unrestricted use, distribution, and reproduction in any medium, provided you give appropriate credit to the original author(s) and the source, provide a link to the Creative Commons license, and indicate if changes were made. The Creative Commons Public Domain Dedication waiver (http://creativecommons.org/publicdomain/zero/1.0/) applies to the data made available in this article, unless otherwise stated. 


\section{Background}

Carotid endarterectomy (CEA) is a useful surgical treatment for reducing the cerebral infarct risk in patients with carotid artery stenosis [1]. Ischaemic brain injury is one of the most severe complications of CEA, caused by cerebral hypoperfusion during temporary carotid artery clamping [2]. Cerebral hyperperfusion syndrome is also a critical, rare complication [3]. Monitoring of cerebral blood flow is essential to prevent these complications; however, continuous monitoring throughout the entire period of CEA is not easy [4].

Monitoring of the regional cerebral oxygen saturation $\left(\mathrm{SrO}_{2}\right)$ using near-infrared spectroscopy (NIRS) is a noninvasive method to observe the oxygen balance of the brain. $\mathrm{SrO}_{2}$ determined by arterial oxygen saturation, cerebral blood flow (CBF), haemoglobin and cerebral metabolic rate $\left(\mathrm{CMRO}_{2}\right)$ reflect the balance of oxygen supply and demand of brain tissue [5]. Previous studies indicated that it is possible to detect the changes in CBF and predict the occurrence of cerebral ischaemia by monitoring of $\mathrm{SrO}_{2}$ [5-8]. Furthermore, monitoring of $\mathrm{SrO}_{2}$ using NIRS is suggested to be a useful method to detect brain ischaemia during CEA [7].

Sevoflurane and propofol are common agents used to maintain general anaesthesia in CEA. Both agents decrease the $\mathrm{CMRO}_{2}$ in a similar manner, but the effects on the CBF are different. CBF changes in parallel to the $\mathrm{CMRO}_{2}$ - a decrease in $\mathrm{CMRO}_{2}$ is accompanied by a decrease in $\mathrm{CBF}$, and vice versa. However, sevoflurane per se has a vasodilatory effect and increases the CBF at concentrations > 1 MAC (minimal alveolar concentration). Thus, CBF is abundant compared with $\mathrm{CMRO}_{2}[9,10]$. Meanwhile, propofol has no vasodilatory effect; it decreases the $\mathrm{CBF}$ as $\mathrm{CMRO}_{2}$ is reduced. [9] Moreover, the reduction of $\mathrm{CBF}$ exceeds that of $\mathrm{CMRO}_{2}$ by propofol, resulting in a decrease in the $\mathrm{CBF} / \mathrm{CMRO}_{2}$ ratio $[11,12]$. There have been several reports that the brain oxygen balance is well maintained in sevoflurane anaesthesia compared with that induced by propofol [13-15].

Recent studies measuring cerebral oxygen saturation using NIRS showed higher oxygen saturation in sevoflurane anaesthesia than that induced by propofol [16, 17], suggesting that sevoflurane is better than propofol to maintain the cerebral oxygen balance. However, in these studies, the patients had neither cerebral vascular disease nor deficit of CBF, and the CBF was preserved with both agents from the viewpoint of clinical safety.

In the present study, we hypothesized that the effects of sevoflurane and propofol on $\mathrm{SrO}_{2}$ in patients undergoing CEA with deficits of $\mathrm{CBF}$, were different compared to those without any CBF deficits. The primary outcome of the study was the comparison of the effects of sevoflurane and propofol on $\mathrm{SrO}_{2}$ in patients undergoing CEA with deficits of CBF. Secondary outcome was the occurrence of any neurologic or hemodynamic deterioration.

\section{Methods}

This prospective randomized controlled trial was approved by the institutional ethics committee of our institution (CNUH-2015-159) and registered in the ClinicalTrials.gov (NCT02609087). After receiving the written informed consent, 74 patients (age, 19-80 years) scheduled to undergo CEA under general anaesthesia were randomly allocated into the sevoflurane group or propofol group by a pre-assembled list generated at random using Excel program. The exclusion criteria were patients with American Society of Anesthesiologists (ASA) physical status $\geq 4$ with low cardiac function, anemia, end-stage renal disease, patients who were low oxygen saturation with pulmonary disease, both carotid artery stenosis, and other neurological disease not related to carotid artery disease. This study was conducted in accordance with the Consolidated Standards of Reporting Trials (CONSORT) 2010 statement [18].

\section{General management}

Patients were given triazolam (Halcion ${ }^{\bullet}$; Pfizer Korea, Seoul, Korea) for anxiolysis $1 \mathrm{~h}$ before arriving in the operating room. After arrival in the operating room, 5-lead electrocardiography, pulse oximetry, and non-invasive automatic blood pressure cuff and end-tidal capnography were implemented for basic monitoring. To assess the depth of anaesthesia, BIS ${ }^{\oplus}$ A-2000 ${ }^{\mathrm{rm}}$ (Aspect Medical Systems, Natick, MA, USA) was attached to the forehead, and an INVOS $5100 \mathrm{~B}$ cerebral oximeter using NIRS (Somanetics, Troy, MI, USA) was applied for monitoring of $\mathrm{SrO}_{2}$. The two probes were placed at the forehead just above the bispectral index score (BIS) probe facing the medial margin of the other. For continuous blood pressure monitoring (Deltran; Utah Medical Products, Midvale, UT, USA) and to obtain samples for arterial blood gas analysis, a 20-gauge catheter was placed in the radial artery after local anaesthetic infiltration. TOF-watch ${ }^{\circledR}$ SX (Organon Ireland Ltd., Swords, Co. Dublin, Ireland) was used to measure the acceleration of the adductor pollicis muscle as a means of monitoring proper muscle relaxation.

In the sevoflurane group, general anaesthesia was induced by infusion of remifentanil (Ultiva ${ }^{\circ}$; GlaxoSmithKline Manufacturing; San Polo di Torrile, Italy) using a targetcontrolled infusion (TCI) pump (Orchestra Base Primea; Fresinius, Brezins, France) at a target concentration of $3 \mathrm{ng} / \mathrm{dL}$ with bolus injection of $1.5 \mathrm{mg} / \mathrm{kg}$ of propofol (1\% Anepol ${ }^{\circledR}$; Hana Pharmaceutical Co., Seoul, South Korea). After confirmation of the loss of consciousness by testing the eyelid reflex, $0.6 \mathrm{mg} / \mathrm{kg}$ of rocuronium bromide (Esmeron ${ }^{\oplus}$; MSD, Kenilworth, NJ, USA) was given for muscle relaxation. A facemask and manual ventilation were applied until adequate sedation $(B I S<60)$ and muscle relaxation (TOF count 0) were achieved. Endotracheal intubation was then performed. General anaesthesia was maintained with $50 \% \mathrm{O}_{2}$ at $3 \mathrm{~L} / \mathrm{min}$ with 
sevoflurane (Sevofran; Hana Pharmaceutical Co.), with adjustment of the sevoflurane concentration to maintain a BIS value of 40-50. In the propofol group, anaesthesia induction and maintenance were performed by continuous infusion and changing the concentration of propofol (Fresofol $\mathrm{MCT}^{\circ}$; Fresinius Kabi, Granz, Austria) with remifentanil at a concentration of $3 \mathrm{ng} / \mathrm{dL}$ using a TCI pump. After endotracheal intubation, controlled ventilation was established at a tidal volume of $7 \mathrm{~mL} / \mathrm{kg}$ and rate of $12 / \mathrm{min}$ with $\mathrm{FiO}_{2}=0.5$, and end-tidal carbon dioxide $\left(\mathrm{ETCO}_{2}\right)$ was maintained between 35 and $40 \mathrm{mmHg}$ by respiratory rate control.

If mean arterial blood pressure (MAP) decreased by $<55 \mathrm{mmHg}$ or was $\geq 25 \%$ of the baseline value, or the systolic arterial pressure dropped below $90 \mathrm{mmHg}$ [19], $100 \mu \mathrm{g}$ of phenylephrine was injected for correction. Dopamine was infused when hypotension was sustained despite proper anaesthetic depth or if an inotropic agent was required after vessel clamping. If the operator requested, $12.5-25 \mathrm{mg}$ of diluted indocyanine green (Indocyanine Green; Dongin-Dang Pharmaceuticals; Seoul, Korea) was added. At the end of the operation, total infused fluid volume, blood loss, urine output, anaesthesia time, operation time, and vessel clamping time were assessed.

\section{Cerebral oxygen saturation and haemodynamics record}

This study was divided into two stages. The first stage was from induction of anaesthesia to immediately before carotid artery clamping, and the second stage was from carotid artery clamping to the end of surgery. Before induction of anaesthesia, the basal levels of blood pressure, heart rate, oxygen saturation, $\mathrm{BIS}$, and $\mathrm{SrO}_{2}$ in room air were recorded. When haemodynamic stability was established with mechanical ventilation $\left(\mathrm{FiO}_{2}=0.5\right)$ after induction of anaesthesia, blood pressure, heart rate (HR), oxygen saturation, BIS and $\mathrm{SrO}_{2}$ were recorded (post-induction baseline). At 1-min intervals, blood pressure, $\mathrm{HR}$, oxygen saturation, $\mathrm{BIS}, \mathrm{SrO}_{2}, \mathrm{ET}_{\mathrm{CO} 2}$, anaesthetic concentrations, type and dosage of inotropic agent were assessed after skin incision for $10 \mathrm{~min}$. These values were then recorded every $5 \mathrm{~min}$ before carotid artery clamping. After clamping and declamping of the carotid artery, the values were recorded every $1 \mathrm{~min}$ for $10 \mathrm{~min}$, including maximal decrease after carotid artery clamping and maximal increase after declamping of $\mathrm{SrO}_{2}$. The recording interval was then returned to $5 \mathrm{~min}$.

\section{Statistical analysis}

Previous studies in patients free of cerebrovascular disease showed maximal decreases in $\mathrm{SrO}_{2}$ of $9.6 \% \pm 7.7 \%$ in the sevoflurane group and $4.2 \% \pm 7.0 \%$ in the propofol group. Student's $t$-test (2-tail) was performed using the G-power program to calculate the sample size showing the difference of maximal decrease between the two groups (effect size $=0.7338623$ ) and 34 patients per group were required to achieve adequate power $(P=0.05 ; \beta=0.8)$ to detect a difference. Considering possible dropout, $37 \mathrm{pa}$ tients were enrolled per group. Patients' characteristics and intraoperative variables were analysed using Student's $t$-test or Pearson's chi-square test. Changes in $\mathrm{SrO}_{2}$ were analysed using Student's t-test. Continuous variables, including $\mathrm{SrO}_{2}$, BIS, blood pressure and heart rate, were analysed by repeated measures analysis of variance (ANOVA) with time as a within-subject repeated measure and the group as a between-subject variable. Statistical analysis was performed using the IBM SPSS Statistics version 20 statistical package (IBM, Chicago, IL, USA). All data are expressed as means \pm standard deviation. In all analyses, $P<0.05$ was taken to indicate statistical significance.

\section{Results}

Among the 74 patients initially included in the study, 2 patients ( 1 in the sevoflurane group and 1 in the propofol group) with low $\mathrm{SrO}_{2}$ (pre-induction basal value < $50 \%$ and 2 patients in the propofol group that showed sustained hypotension or arrhythmia intraoperatively were excluded (Fig. 1). Patients' characteristics including gender, weight, and height, were similar in both groups. There were no significant differences in intraoperative total fluid administration, blood loss, or urine output between the groups (Table 1). There were no significant differences in preoperative values of $\mathrm{SrO}_{2}$, arterial blood pressure, peripheral arterial oxygen saturation, or heart rate between the groups (Table 2). The mean concentrations of intraoperative anaesthetic agents were $1.36 \pm 0.19 \mathrm{Vol} \%$ for sevoflurane and $2.53 \pm 0.37 \mu \mathrm{g} / \mathrm{mL}$ for propofol. The mean remifentanil concentrations were $2.16 \pm 0.62 \mathrm{ng} / \mathrm{mL}$ in the sevoflurane group and $2.87 \pm 1.0 \mathrm{ng} / \mathrm{mL}$ in the propofol group; the difference was not significant.

\section{Changes from the pre-induction period until carotid artery clamping}

$\mathrm{SrO}_{2}$ increased significantly in both groups after induction of anaesthesia compared with baseline $(P<0.001$ in the sevoflurane group and $P=0.012$ in the propofol group). However, there was no difference in the change in $\mathrm{SrO}_{2}$ between the groups (Fig. 2a). The mean value of the relative change in $\mathrm{SrO}_{2}$ was higher $(P=0.033)$ and the maximal decrease in $\mathrm{SrO}_{2}$ was lower in the sevoflurane group compared with the propofol group $(P=0.019)$ in the contralateral site. However, there is no difference in ipsilateral site (affected site) (Table 3). MAP, HR and BIS were similar from induction until 30 min after skin incision, and there were no differences between the groups (Fig. 2). 


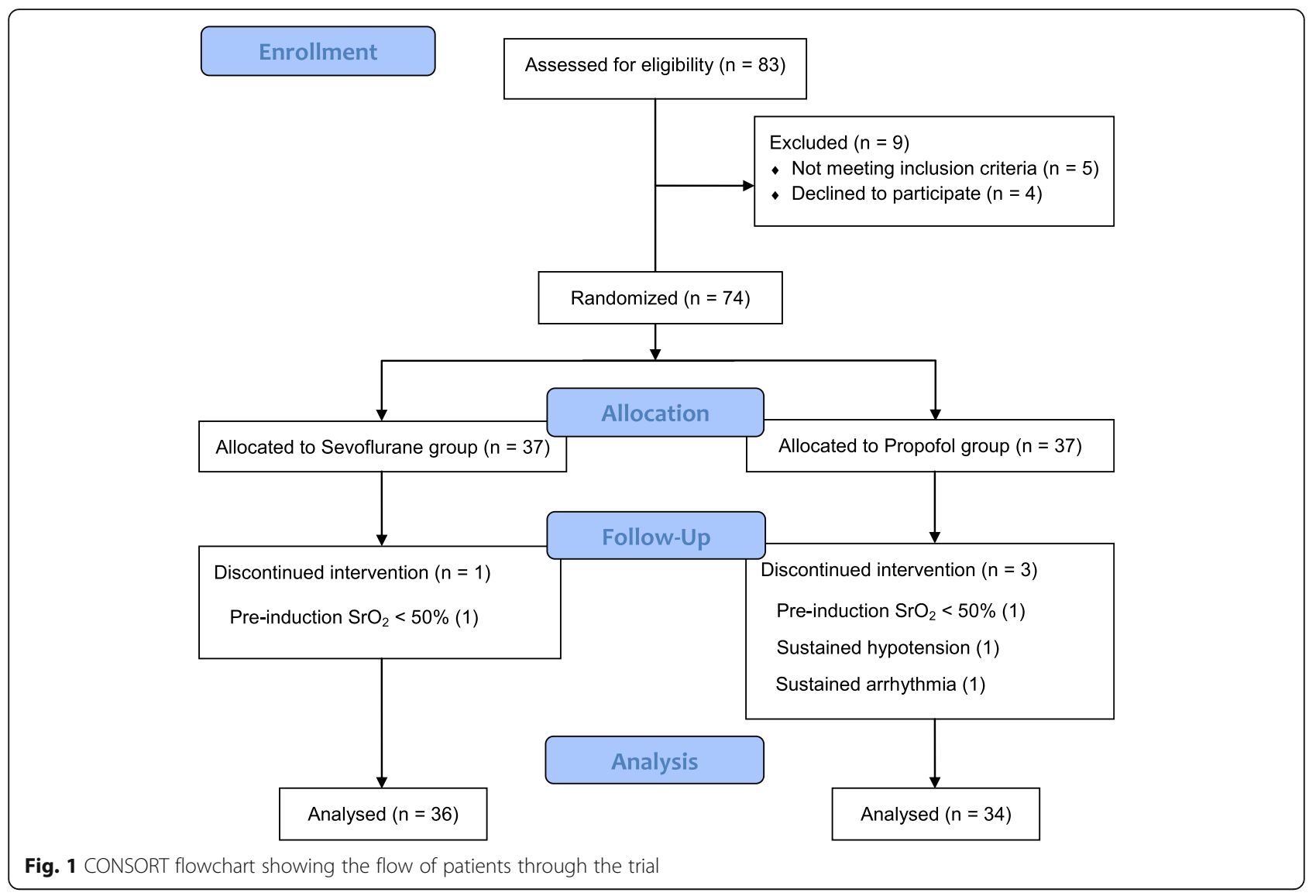

Table 1 Patients Characteristics and Intraoperative Variables

\begin{tabular}{llll}
\hline & Sevoflurane $(n=36)$ & Propofol $(n=34)$ & $P$ value \\
\hline Sex (Male/Female) & $31 / 5$ & $27 / 6$ & 0.562 \\
Age (yrs) & $69 \pm 8$ & $67 \pm 7$ & 0.212 \\
Height (cm) & $163 \pm 7$ & $164 \pm 7$ & 0.322 \\
Weight (kg) & $64 \pm 10$ & $66 \pm 10$ & 0.513 \\
Hemoglobin (g/dL) & $12 \pm 1$ & $13 \pm 1$ & 0.273 \\
Underlying diseases & & & \\
$\quad$ Hypertension & 30 & 24 & 0.413 \\
$\quad$ DM & 13 & 15 & 0.389 \\
Total anesthesia time & $181 \pm 29$ & $174 \pm 26$ & 0.914 \\
Total operation time & $161 \pm 19$ & $158 \pm 17$ & 0.806 \\
Artery clamping time & $39 \pm 8$ & $38 \pm 10$ & 0.401 \\
Fluid administered (mL) & $1412 \pm 377$ & $1618 \pm 441$ & 0.069 \\
\multicolumn{1}{c}{ Crystalloid } & $338 \pm 218$ & $256 \pm 237$ & 0.201 \\
Colloid & $90 \pm 42$ & $116 \pm 72$ & 0.159 \\
Bleeding (mL) & $577 \pm 279$ & $762 \pm 400$ & 0.109 \\
Urine (mL) & &
\end{tabular}

Values are mean \pm SD or numbers

\section{Changes from cardioid artery clamping until the end of surgery}

$\mathrm{SrO}_{2}$ decreased significantly after carotid artery clamping in both groups $(P<0.001)$, but there was no difference between the two groups $(7.6 \% \pm 4.8 \%$ in the sevoflurane group vs. $7.6 \% \pm 5.3 \%$ in the propofol group, $P=0.857$ ) (Fig. 3a). After carotid artery declamping, $\mathrm{SrO}_{2}$ increased significantly, but there was no difference between the two groups $(10.0 \% \pm 11.3 \%$ in the sevoflurane group vs. $11.8 \% \pm 10.2 \%$ in the propofol group, $P=0.473$ ) (Fig. 3a). The change in MAP was significantly lower in the sevoflurane group than the propofol group after declamping of the carotid artery $(P=0.048)$ (Fig. $3 \mathrm{~b})$. There was no difference in heart rate and BIS score between groups (Fig. 3c and d).

$\mathrm{SrO}_{2}$ decreased by $>20 \%$ of baseline during surgery in one patient in the sevoflurane group and in five patients in the propofol group, but the differences between groups were not statistically significant $(P=0.06)$. The $\mathrm{SrO}_{2}$ of five patients (three in the sevoflurane group and two in the propofol group) fell below $50 \%$. In the preand post-carotid artery periods, $\mathrm{SrO}_{2}$ decreased by $>$ $20 \%$ in two patients. Mild stroke occurred in two patients at postoperative follow-up (one in the propofol group and one in the sevoflurane group), and the $\mathrm{SrO}_{2}$ 
Table 2 Baseline hemodynamic and oximetry values

\begin{tabular}{llll}
\hline & Sevoflurane $(n=36)$ & Propofol $(n=34)$ & $P$ value \\
\hline $\mathrm{SrO}_{2}(\%)-$ Ipsilateral & $64.2 \pm 5.7$ & $66.0 \pm 5.9$ & 0.074 \\
$\mathrm{SrO}_{2}(\%)-$ Contralateral & $64.1 \pm 7.6$ & $67.4 \pm 9.2$ & 0.096 \\
$\mathrm{SpO}_{2}(\%)$ & $97 \pm 2$ & $97 \pm 2$ & 0.407 \\
$\mathrm{Mean}$ arterial pressure $(\mathrm{mmHg})$ & $103 \pm 16$ & $110 \pm 20$ & 0.092 \\
Heart rate (beats/min) & $66 \pm 12$ & $70 \pm 17$ & 0.222 \\
\hline
\end{tabular}

Values are mean $\pm \mathrm{SD}$. $\mathrm{SrO}_{2}=$ regional cerebral oxygen saturation; $\mathrm{SpO}_{2}=$ peripheral arterial oxygen saturation

decreases in each patient were assessed: $18 \%$ of basal level and $26 \%$ of pre-clamping period in a patient in the propofol group; $11 \%$ of basal level and $18 \%$ of preclamping level in a patient in the sevoflurane group. $\mathrm{SrO}_{2}$ increased sharply, $>20 \%$ of basal level, after reperfusion in one patient in the sevoflurane group; however, no neurological disorders were found.

Continuous infusion of dopamine was required for maintenance of MAP in the majority of patients, and there were no differences in dopamine dosage or vasopressor requirements.

\section{Discussion}

Regional cerebral oximetry using NIRS is a non-invasive method to evaluate the balance between cerebral oxygen supply and cerebral tissue oxygen demand [20]. $\mathrm{SrO}_{2}$ indicates the percentage of oxygenated and deoxygenated haemoglobin detected by near-infrared irradiation at two

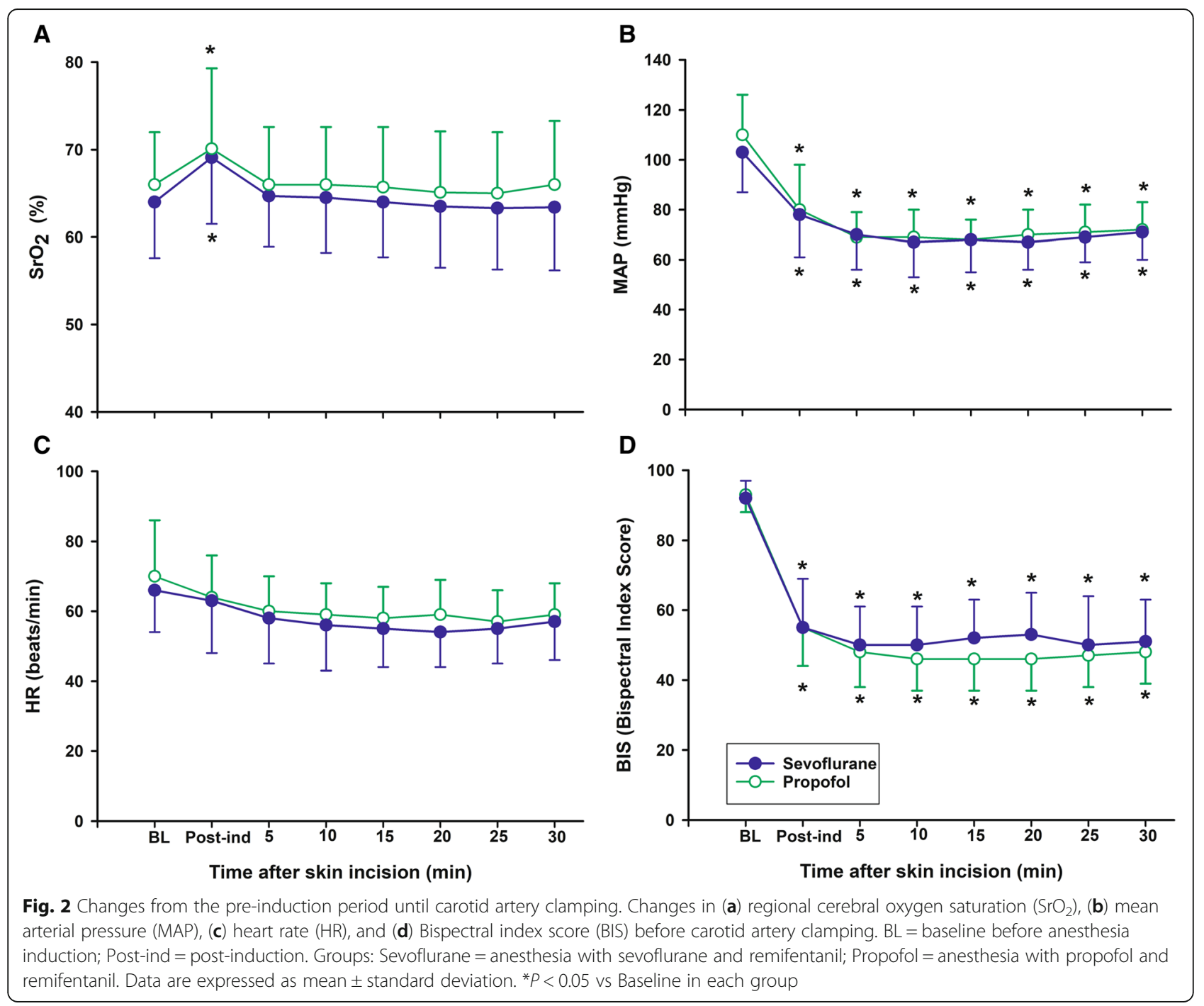


Table $3 \mathrm{SrO}_{2}$ Values in before arterial clamping

\begin{tabular}{|c|c|c|c|}
\hline & Sevoflurane $(n=36)$ & Propofol $(n=34)$ & $P$-value \\
\hline \multicolumn{4}{|l|}{ Ipsilateral } \\
\hline Mean $\mathrm{SrO}_{2}(\%)$ & $63.9 \pm 6.6$ & $65.3 \pm 6.4$ & 0.452 \\
\hline Minimum $\mathrm{SrO}_{2}(\%)$ & $61.8 \pm 6.6$ & $63.1 \pm 7.1$ & 0.407 \\
\hline \multicolumn{4}{|c|}{ Mean value of relative changes in $\mathrm{SrO}_{2}$} \\
\hline compare to baseline (\%) & $1.3 \pm 8.0$ & $-1.6 \pm 8.0$ & 0.237 \\
\hline \multicolumn{4}{|c|}{ Relative maximum decrease in $\mathrm{SrO}_{2}(\%)$} \\
\hline compare to baseline & $3.3 \pm 8.8$ & $4.8 \pm 9.7$ & 0.504 \\
\hline compare to post-induction & $9.9 \pm 6.2$ & $8.1 \pm 6.2$ & 0.250 \\
\hline \multicolumn{4}{|l|}{ Contralateral } \\
\hline Mean $\mathrm{SrO}_{2}(\%)$ & $67.1 \pm 7.5$ & $67.3 \pm 6.9$ & 0.452 \\
\hline Minimum $\mathrm{SrO}_{2}(\%)$ & $66.3 \pm 8.0$ & $66.3 \pm 7.1$ & 0.992 \\
\hline \multicolumn{4}{|c|}{ Mean value of relative changes in $\mathrm{SrO}_{2}$} \\
\hline compare to baseline (\%) & $9.1 \pm 20$ & $-1.9 \pm 22$ & 0.033 \\
\hline \multicolumn{4}{|c|}{ Relative maximum decrease in $\mathrm{SrO}_{2}(\%)$} \\
\hline compare to baseline & $-3.9 \pm 10.1$ & $0.7 \pm 10.5$ & 0.019 \\
\hline compare to post-induction & $4.4 \pm 3.7$ & $6.6 \pm 5.1$ & 0.038 \\
\hline
\end{tabular}

Values are mean $\pm \mathrm{SD}$. $\mathrm{SrO}_{2}=$ regional cerebral oxygen saturation

different wavelengths passing through the skull. The near-infrared irradiation used for NIRS shows high penetrability through the scalp and skull, and therefore can reach deep brain tissue for cerebral oxygen saturation measurements of tissue layers including arterial blood, venous blood, and frontal lobe tissue supplied by the anterior cerebral artery and middle cerebral artery. NIRS is a convenient, rapid, non-invasive and continuous method that is superior to other monitoring devices; as such, it is commonly used to monitor cerebral ischaemia and infarction during neuro- or cardiac surgery [21] and in high-risk operations [22].

However, there are limitations for NIRS, such as localised reflection of oxygen saturation only in focal areas and large interindividual differences due to extracranial blood flow including the scalp. The numerical data from NIRS cannot be interpreted as simple numbers due to the different reference values in individual patents affected by systemic arterial oxygen saturation, CBF, haemoglobin concentration and cerebral oxygen metabolic rate. Although the limitations restrict the assessment of recorded $\mathrm{SrO}_{2}$ as an absolute value, cerebral ischaemia can be detected and prevented by continuous monitoring of $\mathrm{SrO}_{2}$ changes. Samra et al. reported that a decrease in $\mathrm{SrO}_{2}>20 \%$ of the basal level indicates the occurrence of neurological disorder with $80 \%$ sensitivity and $82 \%$ specificity [23]. Michel et al. reported that NIRS can recognise cerebral ischaemia during carotid artery clamping in CEA patients with $80 \%$ sensitivity and $94 \%$ specificity, and it is $6.5 \mathrm{~min}$ faster than the somaticevoked potential [24].
In the present study, $\mathrm{SrO}_{2}$ increased rapidly with induction and endotracheal intubation until carotid artery clamping, and then slowly returned to baseline while preparing for surgery. This may be accompanied by increased oxygen supply due to ventilation through the endotracheal tube $\left(\mathrm{FiO}_{2}=0.5\right)$ after breathing room air $\left(\mathrm{FiO}_{2}=0.21\right)$ and decreased cerebral oxygen metabolism due to general anaesthesia. A previous study in healthy volunteers showed a similar pattern of $\mathrm{SrO}_{2}$ changes to those seen in the present study [25].

Mean and minimal $\mathrm{SrO}_{2}$ were similar between both groups from induction and incision until carotid artery clamping. $\mathrm{SrO}_{2}$ was influenced by the basal level $(P<$ 0.001), and average values of $\mathrm{SrO}_{2}$ change compared with the basal level were not different between the two groups at the ipsilateral side (affected side). However, there was a difference between the two groups at the contralateral side (normal side), with a $9.1 \%$ increase in the sevoflurane group and $1.9 \%$ decrease in the propofol group, and the maximal decrease after induction was significantly different between the two groups.

The effects of sevoflurane and propofol on CBF are different. Both agents decrease cerebral oxygen metabolic rate by a similar amount and, as a result, oxygen demand is reduced and $\mathrm{CBF}$ is also decreased. Sevoflurane decreases CBF at concentrations < 1 MAC (minimum alveolar concentration; sevoflurane $=2 \mathrm{Vol} \%$ ) but increases CBF at concentrations > 1 MAC $[9,26]$, which are thought to be due to the cerebral vasodilation effects of sevoflurane and cerebral autoregulation [27, 28]. Meanwhile, propofol decreases CBF in a dose-dependent manner [12, 29]. 


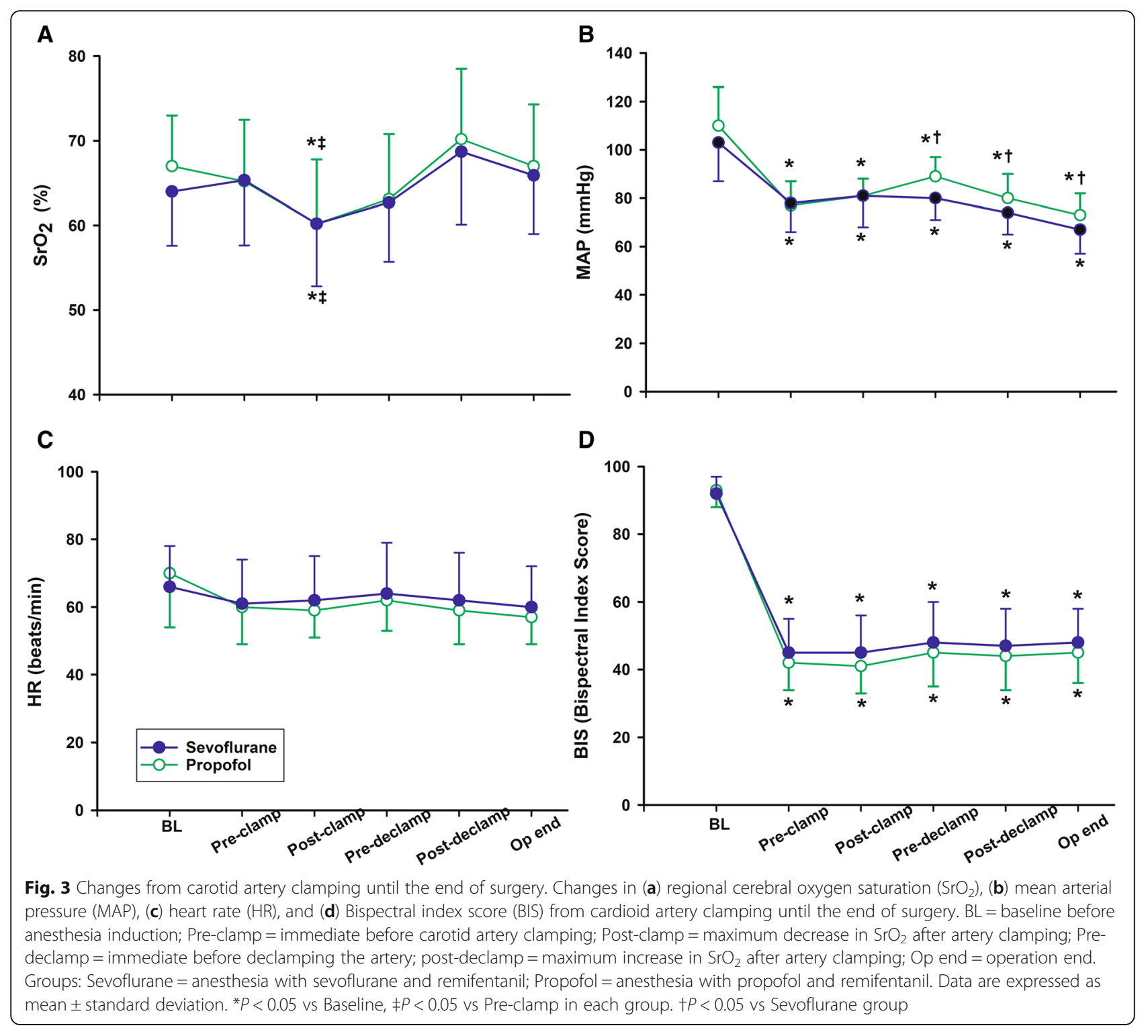

In the present study, sevoflurane was administered at a concentration <1 MAC throughout the entire operation time, and the mean sevoflurane concentration was 1.36 vol\%. This result suggests that the effect of sevoflurane on change in CBF may be reduced compared with the pre-induction period. However, $\mathrm{SrO}_{2}$ was elevated compared with the baseline, which was thought to be due to increased oxygen supply and decreased cerebral oxygen metabolic rate. The mean value of the relative change in $\mathrm{SrO}_{2}$ and maximal decrease were significantly higher in the sevoflurane group than the propofol group. This may have been because the decrease in CBF by propofol is more profound than that by sevoflurane, although the decrease in $\mathrm{CMRO}_{2}$ was similar between the two agents.

Interestingly, the $\mathrm{SrO}_{2}$ change only occurred on the contralateral but not the ipsilateral side, and there was no significant difference on the ipsilateral side in the peri-clamping period between the two groups. This was associated with differences in drug responses between ipsilateral and contralateral sides. Severe internal carotid artery stenosis induces blood-brain barrier injury and impairs the autoregulation to interrupt vasodilation or vasoconstriction on the ipsilateral side. McCulloch et al. reported stump pressure elevation of the clamped ipsilateral carotid artery after switching anaesthetic agent from sevoflurane to propofol in patients with CEA, and they assumed that this was caused by the vasodilation effect of sevoflurane and vasoconstriction effect of propofol [29]. Simultaneously, the middle CBF rate was decreased when anaesthetic agent was changed from sevoflurane to propofol (ipsilateral side, $53 \pm 22 \rightarrow 43 \pm 17 \mathrm{~cm} / \mathrm{s}, n=14$; contralateral side, $53 \pm 19 \mathrm{~cm} / \mathrm{s} \rightarrow 37 \pm 7 \mathrm{~cm} / \mathrm{s}, n=7$ ). In 
another group, the agent was changed from propofol to sevoflurane, and the internal carotid artery pressure was decreased to a lesser degree when the middle cerebral artery flow rate remained constant (ipsilateral side, $51 \pm 22 \rightarrow$ $52 \pm 25 \mathrm{~cm} / \mathrm{s}$; contralateral side, $43 \pm 15 \rightarrow 49 \pm 17 \mathrm{~cm} / \mathrm{s}$ ). Although this result was not statistically significant due to the small sample size, the observation suggested that the affected brain vessels tended to show a lower drug response than those on the contralateral side.

The observation that the data difference between both agents was significant only on the contralateral (non-affected) side may have been due to decreased reactivity on the ipsilateral (affected) side in patients with carotid artery stenosis. Further studies are needed to determine the precise reasons for these results, because CBF rate was not measured in our study and $\mathrm{SrO}_{2}$ can be influenced by many other factors. After carotid artery clamping in our study, $\mathrm{SrO}_{2}$ changes showed no significant differences in both groups. Previous studies indicated that $\mathrm{SrO}_{2}$ remained higher with sevoflurane than propofol [25], and sevoflurane was considered to secure a wider safety margin than propofol when CBF was decreased $[16,17]$.

However, the effects of propofol and sevoflurane on $\mathrm{SrO}_{2}$ were not different after carotid artery clamping in the present study. These discrepancies in the results were likely due to differences in the methods used. Previous studies examined $\mathrm{SrO}_{2}$ changes in healthy volunteers or patients with global CBF reduction in the head elevation position, whereas only collateral vessels were supplied because a large vessel was clamped and main CBF was blocked in the present study. During the vessel clamping period, $\mathrm{SrO}_{2}$ was decreased by $7.5 \%$ compared with the pre-clamping period in both groups in the present study. These observations indicated that cerebral blood supply from the collateral artery could not satisfy the cerebral demand resulting in increased collateral blood flow to compensate for blockage of the main blood flow by clamping. This cerebral haemodynamic state offset the reactions of sevoflurane and propofol to $\mathrm{CBF}$, or blunted the vessel reactivity to both agents.

Another consideration of our study is the effect of intraoperative shunt flow during clamping. Intraoperative carotid bypass (shunt) was not conducted in all patients in the present study. Although placement of carotid artery shunt can increase $\mathrm{SrO}_{2}$ especially in symptomatic carotid disease patients [30], the optimal threshold of $\mathrm{SrO}_{2}$ for selective shunting using NIRS have not been established [31]. Furthermore routine or selective shunting has no evidence for the better neurologic outcome comparing with no shunting [32]. As a result, haemodynamic control for prevention of stroke guided by evoked potential monitoring during clamping is used instead of shunting in our institution.
In the present study, postoperative mild stroke occurred in two patients, one of whom showed a decrease in $\mathrm{SrO}_{2}>20 \%$ of the basal level (sensitivity, 50\%), while decreases of $>20 \%$ in $\mathrm{SrO}_{2}$ occurred in six patients in the entire study population (positive predictive value, $17 \%)$. Sensitivity of $80 \%$ was achieved in a previous study in patients undergoing CEA with regional anaesthesia (deep or superficial cervical plexus block) [23], and the results were revised in a large cohort study performed in 549 patients with general anaesthesia showing 30\% sensitivity, $98 \%$ specificity, and $37 \%$ positive predictive value [33]. Our study with $50 \%$ sensitivity and $17 \%$ positive predictive value in a relatively small cohort should be repeated in larger numbers of patients to achieve greater reliability.

With the exception of two patients in the propofol group, inotropic agents were used to maintain blood pressure within the normal range in other patients in our study population. Haemodynamic instability often occurs in patients with CEA, and impairment of haemodynamic autoregulation by blunted baroreceptor sensitivity due to carotid artery atherosclerosis is common. In addition, advanced age and medications for comorbidities, such as hypertension or diabetes, are associated with haemodynamic instability. Propofol maintained a higher mean arterial pressure than sevoflurane after carotid artery clamping in this study. The benefit of propofol over sevoflurane with regard to haemodynamic stability was not confirmed, despite many previous studies in various clinical settings. Furthermore, in this study, inotropic agents were necessary to maintain stable arterial blood pressure in both groups, and variation of mean arterial blood pressure tended to be uneven. Therefore, we cannot conclude that propofol is a better agent than sevoflurane for providing haemodynamic stability in patients with $\mathrm{CEA}$, and further research is required.

\section{Conclusions}

Propofol-remifentanil anesthesia was comparable with sevoflurane-remifentanil anesthesia in an aspect of preserving the $\mathrm{SrO}_{2}$ in patients undergoing carotid endarterectomy.

\section{Abbreviations \\ BIS: Bispectral index score; CBF: Cerebral blood flow; CEA: Carotid endarterectomy; $\mathrm{CMRO}_{2}$ : Cerebral metabolic rate; HR: Herat rate; MAP: Mean arterial pressure; NIRS: Near-infrared spectroscopy; $\mathrm{SrO}_{2}$ : Regional cerebral oxygen saturation}

\section{Acknowledgements \\ None.}

Ethics approval and consent to patrticipate

This study was approved by the Institutional Review Board of Chonnam National Universtiy Hospital (CNUH-2015-1159), and written informed consenst was obtained from all patients. 


\section{Author's contributions}

SJ, KYY designed the study. SJ and SP drafted manuscript. SP and YWY performed study and obtained data. SJ and HBB performed statistical analysis. KY, JIC and BJ assisted literature search and data collection. JIC and HBB reviewed statistical analysis. All authors read and approved the final manuscript.

\section{Funding}

This study was supported by a grant (CRI15020-1) Chonnam National University Hospital Institute for Biomedical Science. None of funding bodies had any influence on the design of the study and collection, analysis, and interpretation of data and in writing the manuscript.

\section{Availability of data and materials}

The datasets used and analysed during the current study are available from the corresponding author on reasonable request.

\section{Consent for publication}

Not applicable

\section{Competing interests}

The authors declare that they have no competing interest.

Received: 26 April 2019 Accepted: 1 August 2019 Published online: 17 August 2019

\section{References}

1. Silver FL, Mackey A, Clark WM, Brooks W, Timaran CH, Chiu D, Goldstein LB, Meschia JF, Ferguson RD, Moore WS, et al. Safety of stenting and endarterectomy by symptomatic status in the carotid revascularization endarterectomy versus stenting trial (CREST). Stroke. 2011;42(3):675-80.

2. Henderson RD, Eliasziw M, Fox AJ, Rothwell PM, Barnett HJ. Angiographically defined collateral circulation and risk of stroke in patients with severe carotid artery stenosis. North American symptomatic carotid endarterectomy trial (NASCET) group. Stroke. 2000;31(1):128-32.

3. Bouri S, Thapar A, Shalhoub J, Jayasooriya G, Fernando A, Franklin IJ, Davies $\mathrm{AH}$. Hypertension and the post-carotid endarterectomy cerebral hyperperfusion syndrome. Eur J Vasc Endovasc Surg. 2011;41(2):229-37.

4. Pennekamp CW, Moll FL, de Borst GJ. The potential benefits and the role of cerebral monitoring in carotid endarterectomy. Curr Opin Anaesthesiol. 2011;24(6):693-7.

5. Casati A, Spreafico E, Putzu M, Fanelli G. New technology for noninvasive brain monitoring: continuous cerebral oximetry. Minerva Anestesiol. 2006; 72(7-8):605-25.

6. Bhatia R, Hampton T, Malde S, Kandala NB, Muammar M, Deasy N, Strong A. The application of near-infrared oximetry to cerebral monitoring during aneurysm embolization: a comparison with intraprocedural angiography. J Neurosurg Anesthesiol. 2007;19(2):97-104.

7. Moritz S, Kasprzak P, Arlt M, Taeger K, Metz C. Accuracy of cerebral monitoring in detecting cerebral ischemia during carotid endarterectomy: a comparison of transcranial Doppler sonography, near-infrared spectroscopy, stump pressure, and somatosensory evoked potentials. Anesthesiology. 2007;107(4):563-9.

8. Ogasawara K, Konno H, Yukawa H, Endo H, Inoue T, Ogawa A. Transcranial regional cerebral oxygen saturation monitoring during carotid endarterectomy as a predictor of postoperative hyperperfusion. Neurosurgery. 2003;53(2):309-14 discussion 314-305.

9. Kaisti KK, Metsahonkala L, Teras M, Oikonen V, Aalto S, Jaaskelainen S, Hinkka S, Scheinin H. Effects of surgical levels of propofol and sevoflurane anesthesia on cerebral blood flow in healthy subjects studied with positron emission tomography. Anesthesiology. 2002;96(6):1358-70.

10. Reinsfelt B, Westerlind A, Ricksten SE. The effects of sevoflurane on cerebral blood flow autoregulation and flow-metabolism coupling during cardiopulmonary bypass. Acta Anaesthesiol Scand. 2011;55(1):118-23.

11. Jansen GF, van Praagh BH, Kedaria MB, Odoom JA. Jugular bulb oxygen saturation during propofol and isoflurane/nitrous oxide anesthesia in patients undergoing brain tumor surgery. Anesth Analg. 1999;89(2):358-63.

12. Van Hemelrijck J, Fitch W, Mattheussen M, Van Aken H, Plets C, Lauwers T. Effect of propofol on cerebral circulation and autoregulation in the baboon. Anesth Analg. 1990;71(1):49-54.
13. Iwata M, Inoue S, Kawaguchi M, Takahama M, Tojo T, Taniguchi S, Furuya H. Jugular bulb venous oxygen saturation during one-lung ventilation under sevoflurane- or propofol-based anesthesia for lung surgery. J Cardiothorac Vasc Anesth. 2008;22(1):71-6.

14. Kaisti KK, Langsjo JW, Aalto S, Oikonen V, Sipila H, Teras M, Hinkka S, Metsahonkala L, Scheinin H. Effects of sevoflurane, propofol, and adjunct nitrous oxide on regional cerebral blood flow, oxygen consumption, and blood volume in humans. Anesthesiology. 2003;99(3):603-13.

15. Kawano Y, Kawaguchi M, Inoue S, Horiuchi T, Sakamoto T, Yoshitani K, Furuya H, Sakaki T. Jugular bulb oxygen saturation under propofol or sevoflurane/nitrous oxide anesthesia during deliberate mild hypothermia in neurosurgical patients. J Neurosurg Anesthesiol. 2004;16(1):6-10.

16. Jeong $\mathrm{H}$, Jeong $\mathrm{S}$, Lim HJ, Lee J, Yoo KY. Cerebral oxygen saturation measured by near-infrared spectroscopy and jugular venous bulb oxygen saturation during arthroscopic shoulder surgery in beach chair position under sevoflurane-nitrous oxide or propofol-remifentanil anesthesia. Anesthesiology. 2012;116(5):1047-56.

17. Kim SJ, Kwon JY, Cho AR, Kim HK, Kim TK. The effects of sevoflurane and propofol anesthesia on cerebral oxygenation in gynecological laparoscopic surgery. Korean J Anesthesiol. 2011;61(3):225-32.

18. Schulz KF, Altman DG, Moher D, Group C. CONSORT 2010 statement: updated guidelines for reporting parallel group randomised trials. BMC Med. 2010:8:18.

19. Brain Trauma F, American Association of Neurological S, Congress of Neurological S, Joint Section on N, Critical Care AC, Bratton SL, Chestnut RM, Ghajar J, FF MCH, Harris OA, et al. Guidelines for the management of severe traumatic brain injury. I. Blood pressure and oxygenation. J Neurotrauma. 2007:24(Suppl 1):S7-13.

20. Jobsis FF. Noninvasive, infrared monitoring of cerebral and myocardial oxygen sufficiency and circulatory parameters. Science. 1977;198(4323): 1264-7.

21. Goldman S, Sutter F, Ferdinand F, Trace C. Optimizing intraoperative cerebral oxygen delivery using noninvasive cerebral oximetry decreases the incidence of stroke for cardiac surgical patients. Heart Surg Forum. 2004; 7(5):E376-81.

22. Casati A, Fanelli G, Pietropaoli P, Proietti R, Tufano R, Montanini S, Collaborative Italian study group on Anaesthesia in elderly P, Danelli G, Nuzzi M, Mentegazzi F, et al. Monitoring cerebral oxygen saturation in elderly patients undergoing general abdominal surgery: a prospective cohort study. Eur J Anaesthesiol. 2007;24(1):59-65.

23. Samra SK, Dy EA, Welch K, Dorje P, Zelenock GB, Stanley JC. Evaluation of a cerebral oximeter as a monitor of cerebral ischemia during carotid endarterectomy. Anesthesiology. 2000;93(4):964-70.

24. Michel A, Weigand MA, Eckstein HH, Martin E, Bardenheuer HJ. Measurement of local oxygen parameters for detection of cerebral ischemia. The significance of cerebral near-infrared spectroscopy and transconjunctival oxygen partial pressure in carotid surgery. Anaesthesist. 2000;49(5):392-401.

25. Valencia L, Rodriguez-Perez A, Kuhlmorgen B, Santana RY. Does sevoflurane preserve regional cerebral oxygen saturation measured by near-infrared spectroscopy better than propofol? Ann Fr Anesth Reanim. 2014;33(4):e59-65.

26. Mielck F, Stephan H, Weyland A, Sonntag H. Effects of one minimum alveolar anesthetic concentration sevoflurane on cerebral metabolism, blood flow, and CO2 reactivity in cardiac patients. Anesth Analg. 1999;89(2): 364-9.

27. Ogawa Y, Iwasaki K, Shibata S, Kato J, Ogawa S, Oi Y. The effect of sevoflurane on dynamic cerebral blood flow autoregulation assessed by spectral and transfer function analysis. Anesth Analg. 2006;102(2):552-9.

28. Cho S, Fujigaki T, Uchiyama Y, Fukusaki M, Shibata O, Sumikawa K. Effects of sevoflurane with and without nitrous oxide on human cerebral circulation. Transcranial Doppler study. Anesthesiology. 1996;85(4):755-60.

29. McCulloch TJ, Thompson CL, Turner MJ. A randomized crossover comparison of the effects of propofol and sevoflurane on cerebral hemodynamics during carotid endarterectomy. Anesthesiology. 2007;106(1):56-64.

30. Cuadra SA, Zwerling JS, Feuerman M, Gasparis AP, Hines GL. Cerebral oximetry monitoring during carotid endarterectomy: effect of carotid clamping and shunting. Vasc Endovasc Surg. 2003;37(6):407-13.

31. Pennekamp C, Immink R, den Ruijter $H$, Kappelle L, Bots M, Buhre W, Moll F, de Borst G. Near-infrared spectroscopy to indicate selective shunt use during carotid endarterectomy. Eur J Vasc Endovasc Surg. 2013:46(4):397-403. 
32. Chongruksut W, Vaniyapong T, Rerkasem K. Routine or selective carotid artery shunting for carotid endarterectomy (and different methods of monitoring in selective shunting). Cochrane Database Syst Rev. 2014;6: CD000190.

33. Mille T, Tachimiri ME, Klersy C, Ticozzelli G, Bellinzona G, Blangetti I, Pirrelli S, Lovotti M, Odero A. Near infrared spectroscopy monitoring during carotid endarterectomy: which threshold value is critical? Eur J Vasc Endovasc Surg. 2004;27(6):646-50.

\section{Publisher's Note}

Springer Nature remains neutral with regard to jurisdictional claims in published maps and institutional affiliations.

- fast, convenient online submission

- thorough peer review by experienced researchers in your field

- rapid publication on acceptance

- support for research data, including large and complex data types

- gold Open Access which fosters wider collaboration and increased citations

- maximum visibility for your research: over $100 \mathrm{M}$ website views per year

At $\mathrm{BMC}$, research is always in progress. 